\title{
Incentivizing Survey Response: How Incentive Timing, Response Mode Choice, and Urbanicity Affect Survey Response
}

\author{
Andrew Tracy ${ }^{1 *}$ and Amy Javernick-Will ${ }^{2}$
}

\begin{abstract}
Surveys and questionnaires are common tools used in construction and engineering project organization research, though there is a dearth of literature on how to best conduct surveys of issues related to these topics. In this paper, we analyzed how three factors - choice of response mode, incentive timing, and urbanicity - affect response rate, response speed, and degree of survey completion. The survey design used postal contact to solicit participation in a web survey of the general public in Oklahoma and Colorado regarding oil and gas development and hazards. We found that offering a choice of two response modes (web response or mailed paper response) had no significant effect on response rate, response speed, or the degree of survey completion compared to those only offered the web response option. We also found that the timing of a guaranteed incentive (i.e. receiving a monetary incentive in the initial contact versus in the first follow-up) did not significantly affect response rate or the degree of survey completion but did result in a faster response time. Urbanicity of a target community significantly affected all three measures: urban communities exhibited a higher response rate, quicker response speed, and a greater degree of survey completion as compared to rural households, regardless of mode choice or the timing of the incentive. Findings will help inform researchers who employ household surveys how survey design choices impact public response.
\end{abstract}

\section{Keywords}

Research Methods, Induced Seismicity

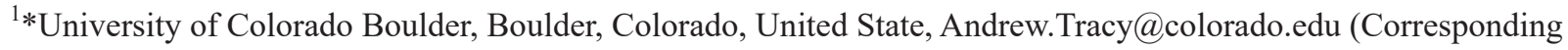
Author)

22University of Colorado Boulder, Boulder, Colorado, United States, Amy.Javernick@colorado.edu
} 


\section{Introduction}

In academic research, surveys are a common tool used to gather data. This holds true for construction research as well, with estimates that nearly a quarter of all articles in a fifteen year window used survey research methods in the Journal of Construction Engineering and Management (Taylor and Jaselskis, 2010). Data gathered from surveys are used in a variety of ways, most commonly for building and testing statistical models (Olivieri et al., 2019), but also for agent-based modelling (Ahn and Lee, 2015) or as part of a mixed-methods study (Hanna et al., 2013; Toole et al., 2013).

In research on construction projects, surveys generally have a target population of project personnel, including labour, field, and project teams (eg, Hacker et al., 2019); while research on construction organisations often target office-based managers (eg, Biswas et al., 2018; Farnsworth et al., 2016; Poleacovschi et al., 2017). Other studies focus on different populations, such as engineering students (Skipper and Brandenburg, 2013) or the general public (Zerio et al., 2016), in order to understand how different audiences perceive aspects of a specific construction project, an organisation, or the built environment broadly.

In short, surveys are widely used in construction research. In order for such surveys to be fruitful in research, however, a significant number of the target population must respond to provide valid results. This is often easier with more niche target populations, such as executives of a specific company, or tradespeople at a specific worksite, but becomes more difficult when seeking participation from the general public. In order to better understand how to obtain responses from these wider study populations, we present the results of a study that used a multi-mode surveying approach to determine what factors affect survey response rate, response speed, and degree of survey completion when surveying the general public via mail. By multi-mode, we mean using different "modes" (eg, mail, telephone, web survey) to contact participants and then record their responses (Millar and Dillman, 2011). The topic of the survey was perceptions of energy infrastructure and associated hazards (earthquakes). We sent the survey to households in communities where these issues are salient, and thus targeted communities that had prominent oil and gas production and seismicity, the associated hazard of interest.

Web surveys are increasingly used to solicit the opinions and perceptions of individuals, both for project based research (eg, Al Qady and Kandil, 2013) as well as in research applications broadly (Dillman et al., 2014; Millar and Dillman, 2011). In web surveys participants are often solicited through an email contact, with a link leading the participant to the web survey. Email contacts are effective when sampling a specific, known group of individuals, such as members of a project team or employees of a specific company, whose email contact information is available to the researcher. However, in order to sample a wider audience, such as the general public, whether at a national level or in a specific geographic region, either a postal, telephone, or in-person contact is often required, even if the survey itself is administered on the web; these are what we are referring to as mixed- or multi-mode surveys.

Few studies, however, have examined the effect of using a mixed-mode approach on response rates, where different "modes" (eg, mail, telephone, web survey) are used to contact participants and then record their responses (Millar and Dillman, 2011 is an exception). Instead, the majority of survey practice literature focuses on using a single mode for both contacting the respondent and conducting the survey, such as contacting individuals via email to participate in a web-based survey (Sauermann and Roach, 2013), or a comparison of two singlemode surveys, such as Zeglovits and Schwarzer (2016) study comparing item non-response in a telephone survey to a similar web survey. Additionally, there is a dearth of literature that examines best survey practices when considering a topic related to civil engineering. Instead, many studies on survey methods and theory deal with more accessible topics, such as opinion polls of elected officials or media consumption habits. Thus, this research contributes to the body of knowledge of survey administration by examining factors that affect response in a survey design that uses a postal contact to solicit participation in a web survey of the general public. The survey is focused on energy infrastructure and associated hazards; specifically, 
perceptions of oil and gas development and human induced earthquakes. In particular, the study examines how altering incentive timing and choice in response mode (ie, responding via a web survey vs having the choice between a web and mailed response) affects response rate, response speed, and the degree to which a survey is completed, and how these effects differ between urban and rural populations.

Though survey research has shown that providing a guaranteed monetary incentive results in a higher response rate (eg, Edwards et al., 2002), there is a lack of research analysing if timing of incentive in the recruitment process affects response. In addition, scholars have theorised that offering multiple choices in response mode might depress response rate due to respondents deferring their decision as to which mode of response to use (Medway and Fulton, 2012; Tversky and Shafir, 1992), but these studies focus on surveys where the "choice" must be made across multiple contacts or rounds of the survey. In our study, respondents were offered a choice only in one follow-up mailing, reducing the number of times respondents must make a choice about how to respond to the survey. Finally, the target population of the study presented here is the general public, in contrast to the many survey practice articles centred on a limited, focused population such as medical professionals or students (eg, Asch et al., 1997; Millar and Dillman, 2011).

Given the costs associated with soliciting the general public to participate in a survey research programme, this research can help survey researchers make time- and cost-effective decisions in developing a survey administration plan to optimise participant response. Therefore, this paper will seek to address the questions via a survey administered to households in Oklahoma and Colorado focused on oil and gas development and the hazard of seismicity: How does incentive timing affect response rate, response speed, and survey completion in a survey of the general public? and How does offering a subsequent choice in response mode affect response rate, response speed, and survey completion in a survey of the general public?
The populations studied in this paper are distinct from each other in that one set of populations can be classified as "urban" while the other is very "rural." This allows us to posit the additional questions: How does the urbanicity of a population affect response rate, response speed, and degree of survey completion? How do these outcomes change when controlling for incentive timing and/or response mode choice?

\section{Background}

Our study uses a survey of the general public to examine how the factors of incentive timing, response mode choice, and urbanicity together affect response rate, response speed, and the degree of survey completion.

\section{Surveying the General Public}

To conduct a survey of the general public, either a mail survey or a random digit dialling (RDD) telephone survey is typically used (Dillman et al., 2014). Despite the continued rise in internet usage by adults over time in the United States ( $89 \%$ of adults overall, at least $90 \%$ in suburban and urban communities, $78 \%$ in rural communities according to Pew Research Center, 2018) there are still adults who do not use or have access to the internet. In addition, even if a researcher was only interested in surveying those with internet access, there is currently no publicly available database of email addresses or any other form of contacting potential respondents directly through the internet.

Some survey platforms and vendors, such as Qualtrics, offer geographic sampling as a service. This can be extremely useful in high population study sites, such as surveying medium and large United States cities (eg, Osman et al., 2019 on willingness to pay for utility services) or a national level survey that does not require more granular regions of analysis (eg, Kaminsky and Faust, 2017 on public perceptions of how utilities are impacted by the refugee crisis in Germany). However, when studying smaller populations, or in studies that require more granularity in analysis, achieving these internet-based geographic quotas from vendors is nearly impossible. 
Additionally, much of the methods literature on surveying the general public using "established" methods such as random digit dialling telephone surveys is out of date, as many households in the United States no longer have landlines, making this method less able to capture the general population than previously thought (Kennedy et al., 2016). Thus, this work seeks to add to the body of knowledge regarding how to survey the general public as they behave now, as opposed to how the public behaved in decades past.

Due to the difficulty in soliciting participation in our geographical survey areas via the web, and due to the higher relative cost and shortcomings of using an RDD telephone survey, we used a postal contact to solicit participation in our survey. In doing so we aim to contribute to literature in providing realistic data on how to sample smaller targeted populations of interest that can otherwise not be sampled effectively.

\section{Experimental Factors}

Studies in survey methods literature have examined a number of factors that are thought to influence survey participation and response. The experimental factors of this study - the timing of a cash incentive, the option to choose between two different response modes, and the urbanicity of our sample - were altered to analyse their effects on our outcomes of interest - response rate, response speed, and the degree to which a survey is completed.

\section{Incentive timing}

Cash incentives have been used to increase survey response for decades. Edwards et al. (2002) conducted a systematic review of 292 surveys across 251 publications and found that surveys with a cash incentive yielded a response rate nearly double that of those that offered no cash incentive. While some researchers have looked at lottery style incentives (eg, Sauermann and Roach, 2013) or offering an incentive after the completed survey is returned, many researchers (eg, Berry and Kanouse, 1987; Delnevo et al., 2004; Dillman et al., 2014) have shown that the non-conditional incentive is the most effective.
The use and effectiveness of nonconditional cash incentives fall in line with the principle of reciprocity in influence theory (Groves et al., 1992) and the theory of social exchange (Emerson, 1976). Though the concepts differ slightly, they are largely similar in how they influence survey development practice. Reciprocity, as defined in influence theory, is the idea that individuals respond to the actions of others in kind, that being the recipient of positive behaviour causes the individual to respond with positive behaviour in turn. Social exchange differs in that it more closely reflects a transaction, in this case the monetary incentive is viewed almost as a "pre-payment" for survey completion, though through this lens the exchange is viewed as less explicit than the "purchase" of participation and relies in part on altruism and developing mutual trust between parties to influence the exchange (Stafford, 2008).

Though there are multiple theories for why survey incentives work, the bulk of survey methods research shows that unconditional cash incentives are effective. However, this past work has not thoroughly examined if the timing of a nonconditional incentive affects participant response; this paper will explore those effects.

\section{Response mode choice}

Smyth et al. (2010) showed that mail response mode yields greater response than a web response when surveying the general public, and that, when given a choice between responding via mail or web, respondents generally preferred mail. Millar and Dillman (2011) had similar findings when surveying a population of undergraduate studentsthe subgroup that received only the option to reply by mail had a higher response rate than those given a choice of mail or web response.

However, internet access and usage has changed significantly since these two studies examined the effects of survey response mode. 12 years after Smyth et al. (2010) administered their survey and 11 years after Millar and Dillman (2011) fielded theirs, internet use by adults had increased by about $15 \%$, even in rural communities (Pew Research Center, 2018), but there is now a gap in literature exploring whether the trends they observed about mail vs internet response modes still hold true. 
Given the added costs to researchers in printing and mailing out physical surveys for respondents to fill out, we explore whether these trends hold today, or if a more internet-savvy public responds more favourably to a web response option.

\section{Urban-Rural divide}

Though recent survey literature discusses the logistical difficulties in surveying rural populations, there is little literature examining if urban and rural populations have different levels of response for the same survey. Steeh (1981) observed that urban populations had greater refusal rates than rural populations in her analysis of surveys from the 1950's and 1970's. While hypotheses are presented to rationalise this finding, including individuals in urban regions being generally less willing to help others than those in rural regions (House and Wolf, 1978; Steblay, 1987), not all subsequent studies have supported these results. For example, Amato (1993) found no significant differences between how willing urban and rural community members were to help others. Given the dearth of recent research in this area, this study will examine differences in survey response in terms of urban and rural respondents.

\section{Factors Held Constant}

In addition to the factors presented above that were actively changed as part of this research, there are numerous other elements of survey design that past research has shown to impact response. Notably, approaches used in our design that did not change are using the language of influence theory; the effect of the sponsoring organisation; and the effect of personalising surveys, explained below. These three factors were primarily present in the letters that were mailed to households to solicit their participation in our study.

\section{Influence theory}

Influence theory outlines six principles that help lead to an individual complying with a request, in our case responding to a survey (Cialdini 1984 qtd. Dillman et al., 2014). For example, the principle of social proof or social validation states that individuals are more likely to take part in an action if others, particularly peers, are also participating. Drawing on this principle, language such as: "Many of your fellow community members have already responded to the survey and we want to make sure that you have the chance to share your opinions as well," are often used in order to increase survey participation. "Scarcity" is another principle used to influence compliance, in the sense that the request is made to a limited number of individuals, and therefore the individual's participation is valuable, or for a limited amount of time. Phrases such as "You are an important source of information about events impacting your town and community," are examples of the principle of scarcity used in survey recruitment scripts. These principles were used in developing the recruitment materials for our survey.

\section{Sponsoring organization}

Denoting that a survey is being conducted or sponsored by a known institution such as a university or government entity has been shown to increase response rate (Dillman et al., 2014; Edwards et al., 2002). Such a connection to a public entity demonstrates that the survey is coming from a valid authority, a factor associated with increased willingness to comply with the survey request (Groves et al., 1992). To that end, our survey made clear the university and department conducting the study, as well as the study's sponsoring organisation.

\section{Personalization of mailings}

Though many scholars (Dillman et al., 2014; Edwards et al., 2002), claim that personalising survey solicitations increases response rates, personalization of mail has become more common, and several studies have shown personalization to have a null, or sometimes negative, effect on response rate, speed, or item non-response (Gendall, 2005; Hawes et al., 1987; Houston and Jefferson, 1975; McKenzie-McHarg et al., 2005). This is especially true in cases where respondents may desire anonymity, such as when surveying on contentious or otherwise sensitive topics. Thus, we did not personalise our recruitment letters. 


\section{Response Outcomes}

In this work we examine how the experimental factors (incentive timing, response mode choice, and urbanicity) affect three elements of survey response: response rate, measured response speed, and the degree of survey completion.

\section{Response rate}

Though there are many researchers who argue that response rate alone is not indicative of the quality of a survey or lack of non-response error, response rate is still often cited in academic articles as just such a measure, particularly as it is difficult and sometimes impossible to estimate non-response error (eg, Groves and Peytcheva, 2008). That said, not every study presents a response rate, for instance, when a third party contractor is used a response rate may not available to the researchers. Response rates also vary greatly by methods, with single digit response rates being seen in mailed surveys of the general public, while in person surveys can report nearly $100 \%$ response. We examine response rate as to serve as a proxy for the efficiency of soliciting participants, which is of practical use for researchers interested in using a mailed survey approach.

\section{Response speed}

While a timely response is not critical in every survey application, it is often desirable and can be important. For a survey where the topic's saliency may ebb over time for the audience, including the survey we sent which asked about recent earthquake events, receiving a response quickly may affect the quality and content of response. For this study, we consider response speed as how long it takes a researcher to receive a response from the survey participants. Therefore, we measure response speed as the number of days it takes from sending out the solicitation to receiving a response, including the time it takes to mail a survey packet to the sample site and the time it takes the survey to be received by the research team, be it via mail or online.

\section{Degree of survey completion}

Lastly, we examine how complete the returned surveys are in terms of the percentage of questions answered. Using a benchmark suggested by the American Association for Public Opinion Research (The American Association for Public Opinion Research, 2016), surveys may be considered "complete" even if they are missing responses to certain questions. That said, it is still the goal of researchers to maximise the number of questions participants respond to beyond this minimum threshold determined by the research team. Surveys were deemed partially complete if the respondent completed less than $80 \%$ of questions but more than $50 \%$ of questions. Surveys were deemed complete if $80 \%$ or more of questions were answered.

\section{Context}

The intent of the survey in question was to measure various perspectives of human-induced earthquakes occurring in the central United States, as well as the theorised cause of the earthquakes (USGS, 2020). These earthquakes are associated with oil and gas production; specifically, they are caused by the disposal of wastewater produced by hydraulic fracturing (Keranen et al., 2014; Yeck et al., 2016), with some studies linking the earthquakes to hydraulic fracturing directly (Rubinstein and Mahani, 2015). Therefore, sites were selected based on having varying levels of earthquake activity and prominent oil and gas development. To that end, the survey was sent to members of the general public in four different geographic areas, two each in Oklahoma and Colorado.

In each state we had one urban target population of approximately 100000 people, representing 30000 households; and a rural target population of between 40000 and 50000 people, with approximately 17000 households. The rural populations were spread over multiple contiguous counties, where the largest town was less than 15000 people but where the majority of the population lived in communities of 5000 or less (US Census Bureau, 2019). By having rural and urban contexts we can examine how urbanicity affects our outcomes. More information about the sites can be seen in Table 1 .

The survey asked questions regarding household perceptions of the increase in the number of human-induced earthquakes in each of the four 
Table 1 Site Information

\begin{tabular}{|c|c|c|c|c|}
\hline State & Site & Urbanicity & $\begin{array}{l}\text { Population ( } 2014 \\
\text { Estimate) }\end{array}$ & $\begin{array}{c}\text { Number of } \\
\text { households } \\
\text { (2013 Estimate) }\end{array}$ \\
\hline \multirow[b]{2}{*}{ Oklahoma } & Edmond & Urban & 88605 & 31233 \\
\hline & $\begin{array}{l}\text { Major, Woodward, Woods, and Alfalfa } \\
\text { Counties }\end{array}$ & Rural & 43614 & 16528 \\
\hline \multirow[b]{2}{*}{ Colorado } & Greeley & Urban & 98596 & 33103 \\
\hline & $\begin{array}{l}\text { Elbert, Washington, Kit Carson, and Yuma } \\
\text { Counties }\end{array}$ & Rural & 48347 & 17248 \\
\hline
\end{tabular}

regions. Due to the association with oil and gas development, the topic is divisive and politicised. Though the high level of oil and gas development in these regions may make issues related to energy development highly salient to individuals, we believe that, due to the contentious nature of both hydraulic fracturing generally and human-induced seismicity in these regions, we expected a lower response rate than obtained with less controversial survey topics (such as the surveys discussed in Millar and Dillman, 2011; Smyth et al., 2014). Low response rates have been observed in studies with similar topics (eg, Grubert, 2018's sampling yielded a $4 \%$ and $8 \%$ response rates) despite the topic's salience to the sample populations.

\section{Research Method}

To test the effect of both incentive timing and response mode choice, three solicitation approaches were developed. Each approach consisted of three "waves" of mailings to the sampled populations. Each wave was a mailed contact, and each sampled household was sent all three waves; the only exceptions were if a household completed the online survey before the next mailing was to be sent out, or if an earlier mailing was returned to sender marked as "Vacant," "Unclaimed," or otherwise undeliverable by the US Postal Service. The waves were done as previous research (eg, Dillman et al., 2014) has demonstrated that multiple reminders, or contacts, can have a significant impact on overall survey response rate. The mailings for each wave were sent out approximately three weeks apart from each other starting in January of 2018. The online survey was kept open until the beginning of May 2018, but no completed responses were received past March of 2018.

The waves for each approach are shown in Table 2.

The difference between Approach 1 and Approach 2 would yield information on whether the timing of a monetary incentive affected response, while the comparison of Approach 1 and Approach 3 would yield information on whether offering an option of response mode affects response. These factors are discussed in detail in the subsequent sections.

Table 2 Mailing Approaches

\begin{tabular}{|l|l|l|l|}
\hline & \multicolumn{1}{|c|}{ Approach 1 } & \multicolumn{1}{c|}{ Approach 2 } & \multicolumn{1}{c|}{ Approach 3 } \\
\hline Wave 1 & Letter & Letter with Incentive & Letter \\
\hline Wave 2 & Letter with Incentive & Letter & Letter, Physical Survey, and Incentive \\
\hline Wave 3 & Letter & Letter & Letter \\
\hline
\end{tabular}

$\mathrm{n}=400$ for each approach. 


\section{Letters}

Letters were included in every wave and approach, asking that the adult resident with the most recent birthday participate in our research by taking a survey. The letters introduced the respondents to the research project, explained why they were solicited, introduced the research team, and provided the contact information of the first author to address any questions or concerns regarding the study.

Each element of the letter was written with language that theory suggests will increase survey response. Drawing on the principle of social proof, the second- and third-wave letters included language such as: "Many of your fellow community members have already responded to the online survey and we want to make sure that you have the chance to share your opinions as well." Using the principle of scarcity, we explicitly stated the time remaining to participate in the survey and in the final wave stated that this is their "last chance to make their voice heard" for this issue.

Each letter included a unique URL that led the respondent to an online version of the survey. Use of a unique URL allowed us to tie participation in the survey to an address and avoid sending reminder letters to households that had already completed the survey. The letters were printed on coloured "University of Colorado College of Engineering and Applied Science" letterhead and denoted that the research was being performed by the University of Colorado and was funded by the National Science Foundation.

As noted previously, a credible sponsoring organisation such as a university is thought to increase survey response. However, the sponsoring university for this study has a reputation as being a "liberal" institution, and the case study communities, even the urban communities, could be considered as more "conservative" areas, so it is difficult to tell if denoting the University affiliation positively or negatively affected the study's perceived legitimacy, particularly given the polarised topic of the survey. Qualitative fieldwork in these communities by the first author revealed that, for many interviewees, presenting the research as an engineering study, as opposed to a social science study, and identifying the funding source, which was a non-partisan federal agency, increased the research team's legitimacy in the region and individuals' willingness to participate in the research. Therefore, the decision was made to also denote the sponsoring department within the university as "Engineering and Applied Sciences" and highlight the National Science Foundation as the funding source. Though a more extensive set of approaches testing the language of the letter for the relationship of these elements and response rate is of interest, financial and logistical constraints prevented us from doing so.

The only differences in the letters for each approach reflected the differences in the response modes available (ie, online only or the choice of online or mailed response) and whether an incentive was present in that mailing (eg, the letter for the first wave of Approach 2 mentioned the "enclosed token of appreciation," referring to the monetary incentive, while the letter for the first wave of Approaches 1 and 3 mention no incentive, as they had not received one with that mailing.)

Because our study surveys the general public regarding a sensitive and politicised issue, we did not personalise solicitations, so as to not suggest that responses were not anonymous. This had the added benefit of reducing the cost to the researchers by being able to purchase a "non-matched" address sample from a vendor.

\section{Physical Survey}

In wave 2 of Approach 3 a physical survey booklet was included, as well as a return-addressed business reply envelope. Because of this, this mailing was sent in a 6"x 9" Window envelope, while every other mailing was sent in a standard \#10 Window envelope. All mailings had a colour logo on the envelope and letterhead, though the survey itself was printed in black and white.

\section{Incentives}

However, Edwards et al. (2002) work also suggests that, although including a $\$ 1$ incentive increases response rate and that larger incentives further increase response rate, these returns diminish as the incentive increases. Thus, providing a high incentive of $\$ 15$ would only result in an odds of response being 2.5 times higher than having no 
incentive at all, while the single dollar incentive resulted in an odds increase of nearly 2 . Cognizant of these diminishing returns, we opted to include a smaller incentive of $\$ 2$. Specifically, we included one $\$ 2$ bill in the mailing. Given the relative rarity of $\$ 2$ bills in circulation in the United States, the bill may serve as a reminder to the participants of our survey (ie, when they see the rare $\$ 2$ bill in their purse or wallet, they are reminded to take the survey, whereas a $\$ 1$ bill would not necessarily elicit the same response). In addition, the $\$ 2$ bill may be viewed as more of a unique gift than a payment, and thus be viewed more along the lines of a positive action that may yield reciprocal action. Our work builds on survey incentive research by examining what effect the timing of this incentive has on survey response.

\section{Sample}

For this study, we needed respondents to live within the geographic bounds of our four case study regions. Although some third-party vendors claim to be able to solicit responses in a specific geographic region through a web contact, vendors contacted for this study anticipated being able to match only $30 \%$ of geographically targeted households with email addresses, and even lower "click" rates, or individuals actually opening the email and survey link, which does not mean completing the survey, with this method. One vendor expected only $1 \%-3 \%$ of emails resulting in people opening the survey link, and another survey contractor anticipated they would receive a total of 19 responses in one of the rural case-study regions, which has a population of about 50000 people (a response rate of $.038 \%$ ). While the estimates were slightly higher for the urban regions, they were still too low to be feasible for our study, necessitating using an Address Based Sampling (ie, "snail mail") approach.

We obtained a stratified random sample of households in each of the four regions for use as the sample frame. 3000 records were procured for each of the four regions to be used for this survey as well as for a future, expanded study. This sample frame was produced such that known P.O. Box, seasonal, commercial, educational, and vacant addresses would not be used. We solicited 300 households for each community, resulting in 1200 solicited households in all. To develop the distribution lists, every $10^{\text {th }}$ address was selected from the initial 3000 records for each region. From these 300 households, every third household was placed into a different approach group, so that smaller geographic subgroups, like neighbourhoods, were not all grouped into the same approach, but rather that the geographic regions would be sampled proportionate to the population distribution within the region. The unused addresses were used in a subsequent survey of the regions.

As pieces of mail deemed undeliverable by the US Postal Service were returned, the addresses were marked as unreachable so that they would not be sent additional follow-ups. The addresses were then sorted according to the USPS endorsement code and the guidelines presented in the American Association for Public Opinion Research's (AAPOR) Standard Definitions (The American Association for Public Opinion Research, 2016) to use in response rate calculations. Completed surveys were recorded as they were returned via mail or were completed online.

\section{Survey Data}

Of the 1200 administered survey questionnaires, we received 114 completed surveys and nine partially completed ${ }^{1}$ surveys. Of the remainder, there were 13 households recorded as "Eligible, non-interview," generally people who notified the research team that they received the mailing but refused to participate; 998 households of unknown eligibility; ${ }^{2}$ and 66 households were "not eligible" to be sampled. ${ }^{3}$ Table 3 summarises these response outcomes by approach and urbanicity.

\footnotetext{
${ }^{1}$ Surveys were deemed partially complete if the respondent completed less than $80 \%$ of questions but more than $50 \%$ of questions. Surveys were deemed complete if $80 \%$ or more of questions were answered. For this paper partials are not considered complete and are not used in the analysis.

${ }^{2}$ ie, no response was received, meaning there was no way to guarantee the address was not valid.

${ }^{3}$ Addresses were generally deemed "not eligible" if the survey was returned to the research team by U.S. Postal Service being noted as "undeliverable" for a variety of reasons, such as the property being vacant.
} 
Table 3 Response Outcomes

\begin{tabular}{|l|c|c|c|c|c|c|}
\hline & \multicolumn{2}{|c|}{ Approach 1 } & \multicolumn{2}{c|}{ Approach 2 } & \multicolumn{2}{c|}{ Approach 3 } \\
\hline Urbanicity & Urban & Rural & Urban & Rural & Urban & Rural \\
\hline Complete & 20 & 12 & 28 & 16 & 24 & 14 \\
\hline Partially Complete & 1 & 2 & 0 & 1 & 0 & 5 \\
\hline Eligible, non-interview & 2 & 2 & 1 & 5 & 2 & 1 \\
\hline Eligibility Unknown & 167 & 172 & 160 & 170 & 159 & 170 \\
\hline Not Eligible & 10 & 12 & 11 & 8 & 15 & 10 \\
\hline
\end{tabular}

The demographic makeup of the sample was fairly representative. Approximately $90 \%$ of the sample identified as white, which is only slightly higher than the general populations of these sites, which are closer to $80 \%$ white (US Census Bureau, 2019). The sample was older than the general population, with a median age of approximately 58 years compared to the national median of 38 years, which is generally the case with surveys of the general public. Gender was evenly split, with $52 \%$ of respondents being female. The median household income fell between $\$ 50000$ and $\$ 74$ 999 per year. By these demographics, this sample is representative of the target population, if slightly older. Due to the variance of these variables and the small sample size, further analysis of response by demographic groups is not possible.

\section{Response Rate}

Across all approaches, the response rate was $10.1 \%$ when using AAPOR's RR1 calculation, which is the ratio of completed surveys to all households known to be eligible and of unknown eligibility. The response rates broken out by approach and urbanicity are shown in Table 4.

\section{Response Speed}

To measure response speed, we recorded how long it took to record a completed response from a household from the date of the initial mailing, as it was impossible to determine with certainty the date mailings would arrive at any given household, and a built in issue of relying on a mail response mode is that it may take longer than a web response. Across all approaches the average response speed was approximately 25.5 days from the initial mailing, with the shortest turnaround being 4 days after the initial mailing and the longest response time being 82 days after the first mailing. These figures only include surveys that were returned completed, so return times for partials, break-offs, or other refusals that were sent to the research team are not included. The breakdown of response speed by approach and urbanicity are shown in Table 5 .

\section{Degree of Survey Completion}

Lastly, for all the surveys that were completed we recorded what percentage of all questions were answered as well as the percentage of questions answered that are critical to our overarching research. This latter category excludes open-ended questions and questions denoted to be optional. There were 135 items in the survey, and 114 of those items were considered "critical." Across all

Table 4 Response Rate

\begin{tabular}{|l||c|c|c|c|c|c|c|c|c|}
\hline \multicolumn{1}{|c|}{} & \multicolumn{3}{c|}{ Approach 1 } & \multicolumn{3}{c|}{ Approach 2 } & \multicolumn{3}{c|}{ Approach 3 } \\
\hline Urbanicity & Total & Urban & Rural & Total & Urban & Rural & Total & Urban & Rural \\
\hline RR1 & $8.50 \%$ & $10.50 \%$ & $6.40 \%$ & $11.50 \%$ & $14.80 \%$ & $8.30 \%$ & $10.10 \%$ & $13.00 \%$ & $7.40 \%$ \\
\hline
\end{tabular}


Table 5 Response Speed

\begin{tabular}{|l|c|c|c|c|c|c|c|c|c|}
\hline Approach & \multicolumn{3}{|c|}{ Approach 1 } & \multicolumn{3}{c|}{ Approach 2 } & \multicolumn{3}{c|}{ Approach 3 } \\
\hline Location & Total & Urban & Rural & Total & Urban & Rural & Total & Urban & Rural \\
\hline Mean Response Speed (days) & 25.2 & 23.2 & 28.5 & 22.0 & 19.1 & 27.2 & 30.9 & 30.2 & 32.2 \\
\hline Standard Deviation (days) & 14.9 & 15.3 & 14.2 & 20.0 & 16.8 & 24.4 & 15.5 & 19.0 & 3.9 \\
\hline
\end{tabular}

approaches and levels of urbanicity, respondents completed approximately $90.5 \%$ of "Total" questions and $98.2 \%$ of "Critical" questions. The percentage of questions answered broken down by approach and urbanicity can be found in Table 6 .

\section{Results}

The results were analysed for statistical significance using the computing language $\mathrm{R}$ and a model comparison approach to statistical analysis (Judd et al., 2017). Regression models were developed examining the effects of incentive timing, response mode choice, and urbanicity on response rate, response speed, and degree of survey completion.

\section{Response Rate}

To determine if the differences in response rate by approach were significant, "response," ie, whether a household completed the survey or not, was viewed as a dichotomous dependent variable. Therefore, a binomial logistic regression was performed so that the likelihood that a participant completed and returned the survey was determined based on the Approach and the participants' state and urbanicity (urban/rural). Binomial logistic regression models were developed using combinations of these variables, and initially comparing these models to a model with no predictor, to determine if deviance was significantly reduced using a factor(s) to predict likelihood of response versus using no factors to predict response. Table 7 lists the models and the residual deviance (error) for each, and whether the residual deviance significantly varies from the null model.

As shown in Table 7, the only models that significantly reduced the model deviance used urbanicity as a predictor. Using urbanicity as a predictor yields a significant relationship (LR $\chi^{2}=9.77, \mathrm{df}=113, P=0.002$ ) and yields an odds ratio of 1.87 when comparing urban households to rural households. This means that urban households were nearly twice as likely as rural households to respond to the survey. This relationship holds when looking at urbanicity controlling for the approach used (LR $\chi^{2}=9.83, \mathrm{df}=111 p=0.002$ ), and using the approach as a predictor does not account for additional deviance.

Using Approach as a predictor without controlling for state or urbanicity, the $\chi^{2}$ analysis showed that there was no significant relationship between response rates of the different approach groups (Likelihood Ratio $\chi^{2}=1.659$, degrees of freedom=112, $P=0.436$ ). Using the household's state to explain the difference in response rate

Table 6 Degree of Survey Completion

\begin{tabular}{|l|c|c|c|c|c||c|c|c|c|}
\hline Approach & \multicolumn{3}{|c|}{ Approach 1 } & \multicolumn{3}{c|}{ Approach 2 } & \multicolumn{3}{c|}{ Approach 3 } \\
\hline Urbanicity & Total & Urban & Rural & Total & Urban & Rural & Total & Urban & Rural \\
\hline \% of Total Questions Answered & $89.3 \%$ & $88.4 \%$ & $91.0 \%$ & $89.7 \%$ & $90.6 \%$ & $88.2 \%$ & $92.5 \%$ & $93.2 \%$ & $91.4 \%$ \\
\hline Standard Deviation & $5.7 \%$ & $6.4 \%$ & $4.1 \%$ & $5.3 \%$ & $4.9 \%$ & $5.8 \%$ & $4.1 \%$ & $4.3 \%$ & $3.6 \%$ \\
\hline $\begin{array}{l}\% \text { of Important Questions } \\
\text { Answered }\end{array}$ & $95.6 \%$ & $94.5 \%$ & $97.6 \%$ & $95.8 \%$ & $96.2 \%$ & $95.0 \%$ & $97.8 \%$ & $97.9 \%$ & $97.7 \%$ \\
\hline Standard Deviation & $5.3 \%$ & $6.0 \%$ & $3.4 \%$ & $4.1 \%$ & $3.8 \%$ & $4.7 \%$ & $3.1 \%$ & $2.3 \%$ & $4.3 \%$ \\
\hline
\end{tabular}


Table 7 Residual Deviance of Models and Level of Significance Versus Null Model

\begin{tabular}{|l|l|c|c|c|}
\hline & \multicolumn{1}{|c|}{ Variables } & Deviance & \multicolumn{1}{c|}{$\boldsymbol{P}$} & $\begin{array}{c}\text { McFadden pseudo } \\
\text { R2 }\end{array}$ \\
\hline Null Model & None & 744.29 & - & 0.00 \\
\hline Model 1 & Incentive Timing & 743.07 & 0.27 & 0.00 \\
\hline Model 2 & Mode Choice & 743.88 & 0.52 & 0.00 \\
\hline Model 3 & Urbanicity & 734.52 & 0.00 & 0.01 \\
\hline Model 4 & State & 742.84 & 0.23 & 0.00 \\
\hline Model 5 & Incentive Timing Mode Choice & 742.64 & 0.44 & 0.00 \\
\hline Model 6 & Incentive Timing, Mode Choice, State & 741.17 & 0.37 & 0.00 \\
\hline Model 7 & Urbanicity, Incentive Timing, Mode Choice & 732.80 & 0.01 & 0.02 \\
\hline
\end{tabular}

produced no significant relationship whether serving as a predictor on its own (LR $\chi^{2}=1.452$, $\mathrm{df}=113, P=0.228$ ) or in conjunction with using the approach group as a predictor $\left(\mathrm{LR} \chi^{2}=1.464, \mathrm{df}=111\right.$, $P=0.226)$. After multiple model comparisons it was clear that the only variable of interest that had a significant effect was the urbanicity of the respondent, therefore not all model comparisons are discussed here.

The values presented in the prior paragraph are for the "RR1" rate. Analysis using the RR3 rate, which is the ratio of completed surveys to the number of households that are estimated to be eligible plus those known to be eligible, yields results consistent with those found using RR1, and therefore are not displayed here.

From our analysis of response rate, we can conclude that whether the target population is in an urban or rural region does affect response rate, and that urban populations are more likely to respond than those in rural populations. This remains true when controlling for offering a choice in response mode and when varying the timing of offering a cash incentive. This split between urban and rural response rates contrasts with past literature reporting that urban respondents were less likely to respond to a survey request (Steeh, 1981).

Neither of the other two factors examined in this study, incentive timing and response mode choice, were significant predictors of the odds of a participant responding. Therefore, we cannot say that altering the timing of giving participants an incentive or offering a choice in response mode significantly impacts response rate.
Based on past literature by Smyth et al. (2014) and Millar and Dillman (2011) we would expect the approach that offered the option to respond by mail would yield a statistically significant higher response rate than the approach that offered only a web option, holding the timing of the incentive constant. Given that there was no statistically significant difference this could suggest that the increase in internet usage among adults in the United States may enable similar response rates for online surveys as for surveys using a mailed response.

\section{Response Speed}

Response speed and degree of survey completion were measured as continuous variables. For this reason, a linear regression model was developed looking for a relationship between the response speed and the approach to determine if factor, ie, either incentive timing or the option of an alternative response mode, served as a significant predictor of response speed. We found that there was a weak trend $(P=0.098)$ that those who received the incentive in the first mailing (Approach 2) responded to the survey about five and a half days before those who received the incentive with the second mailing (Approach 1). These results held when controlling for the respondent's urbanicity and whether the household was offered an alternative response mode, ie, including Approach $3(P=0.091)$. As for response mode choice, respondents who had the option of responding online or via the mail took longer to respond than 
Table 8 Regression Coefficients Modelling Response Speed

\begin{tabular}{|c|c|c|c|c|c|c|c|c|}
\hline & \multicolumn{6}{|c|}{ Independent variables (Estimate, $P$ ) } & \multicolumn{2}{|c|}{ Model fit } \\
\hline & \multicolumn{2}{|c|}{ Incentive Timing } & \multirow{2}{*}{\multicolumn{2}{|c|}{$\begin{array}{c}\text { Mode Choice } \\
-\end{array}$}} & \multicolumn{2}{|c|}{ Urbanicity } & \multirow{2}{*}{$\frac{\text { F-Statistic }}{2.78}$} & \multirow{2}{*}{$\frac{\mathbf{R 2}}{0.02}$} \\
\hline Model 1 & 5.50 & 0.098 & & & & & & \\
\hline Model 2 & & & 6.03 & 0.152 & & & 2.08 & 0.02 \\
\hline Model 3 & & & & & 6.03 & 0.071 & 3.33 & 0.03 \\
\hline Model 4 & 5.59 & 0.091 & 6.16 & 0.140 & & & 2.51 & 0.04 \\
\hline Model 5 & 5.39 & 0.102 & & & 5.92 & 0.074 & 3.05 & 0.05 \\
\hline Model 6 & & & 6.07 & 0.145 & 6.05 & 0.068 & 2.76 & 0.05 \\
\hline Model 7 & 5.95 & 0.094 & 6.19 & 0.134 & 5.96 & 0.071 & 2.82 & 0.07 \\
\hline
\end{tabular}

those who could only respond online, but these results were not significant $(P>0.1)$ and did not change when controlling for the other variables. However, when looking just at responses in the Approach three subgroup, those that responded via mail took approximately ten days longer for their response to be received than those that responded online, and this is significant $(P=0.02)$.

Whether a household was in an urban or rural community was also a significant predictor of how quickly they would respond. Urban responses were received six days before the responses from rural households when urbanicity was used as the sole predictor of response speed $(P=0.071)$. This relationship remained significant, when controlling for when households received the incentive and being offered a choice of response mode. Models were developed to evaluate the effect of a factor independently and controlling for the other factors of interest. The regression coefficients for the models we compared are shown in Table 8.

Part of these findings may be explained by the fact that mail may often take longer to be routed to rural addresses than to urban addresses, and not that rural households are any more or less willing to help than urban households, as posited by Amato (1993). This is an issue that cannot necessarily be controlled by a researcher, but the delay in response can be lessened by providing an incentive in the initial mailing.

\section{Degree of Survey Completion}

There were no significant differences in the degree of survey completion by approach $(P>0.4)$.
However, we found that urbanicity mattered, in that there was a significant relationship between the number of questions answered overall and whether the respondent was from a rural or urban household. When analysing urbanicity on its own, urban households responded to about seven more questions than rural households, or about $5 \%$ more complete; this holds when controlling for both incentive timing and mode choice $(P=0.001)$. The full list of the relevant coefficients for the models we examined is shown in Table 9.

When we examined only the completion of the "Critical" questions for the survey, we found that the approach used had no significant effect on the degree of survey completion $(P>0.3)$. However, urban households responded to approximately $4.7 \%$ more important questions, about six questions, than respondents from rural households $(P=0.005)$. This result held when controlling for approach $(P=0.005)$. Table 10 shows the coefficients of the regression models developed to examine this item.

As with response rate, the approach used had no significant relationship with the number of questions households answered in the survey. Whether the respondent was from an urban or rural community was a statistically significant predictor of how many questions they would complete, though the effect was small, as urban households responded to only about $5 \%$ more of the questions than rural households, which for our survey meant a range of about 6-7 more questions out of 135 total items. This again contradicts past survey literature suggesting urban respondents have more distractions and are less willing to help 
Table 9 Effect of Factors on Total Percentage of Questions Completed

\begin{tabular}{|c|c|c|c|c|c|c|c|c|}
\hline & \multicolumn{6}{|c|}{ Independent variables (Estimate, $P$ ) } & \multicolumn{2}{|c|}{ Model fit } \\
\hline & \multicolumn{2}{|c|}{ Incentive Timing } & \multirow{2}{*}{\multicolumn{2}{|c|}{$\begin{array}{c}\text { Mode Choice } \\
-\end{array}$}} & \multirow{2}{*}{\multicolumn{2}{|c|}{$\frac{\text { Urbanicity }}{-}$}} & \multirow{2}{*}{$\begin{array}{c}\text { F-Statistic } \\
0.47\end{array}$} & \multirow{2}{*}{$\frac{\mathbf{R 2}}{0.00}$} \\
\hline Model 1 & $-1.2 \%$ & 0.494 & & & & & & \\
\hline Model 2 & & - & $1.4 \%$ & 0.499 & & & 0.50 & 0.00 \\
\hline Model 3 & & - & & & $-5.4 \%$ & 0.001 & 11.36 & 0.08 \\
\hline Model 4 & $-1.2 \%$ & 0.468 & $1.5 \%$ & 0.472 & & & 0.49 & 0.01 \\
\hline Model 5 & $-0.9 \%$ & 0.572 & & & $-5.3 \%$ & 0.001 & 5.81 & 0.07 \\
\hline Model 6 & & - & $1.6 \%$ & 0.408 & $-5.4 \%$ & 0.001 & 6.01 & 0.08 \\
\hline Model 7 & $-1.0 \%$ & 0.539 & $1.7 \%$ & 0.389 & $-5.4 \%$ & 0.001 & 411 & 0.07 \\
\hline
\end{tabular}

researchers in participating in surveys (eg, Steeh, 1981).

\section{Limitations}

Within this study, the topics of energy development and human induced seismicity were relevant to our sample population, yet also politicised and divisive - a rather abnormal situation for a survey methods study where the topic is often much more innocuous. This may explain, at least in part, why the survey received a low response rate, overall, when compared with the rates often presented in survey practice literature. That said, these rates may be realistic for researchers asking the general public about similarly salient yet sensitive topics, as low, sometimes single digit response rates have been seen before in similar surveys about perceptions of oil and gas development (Grubert,
2018). In other civil engineering research, surveys of the public deal with similarly difficult issues such as sustainable transportation, land use, and water reclamation (eg, Al Hurr and Tashman, 2019; Garcia-Cuerva et al., 2015; Lee, 2016, respectively). Therefore, despite this limited sample size we believe this study may be more representative of work engineering researchers conduct than those presented elsewhere in survey practice literature.

An additional factor that may contribute to our low response rate is survey length. Though we used multiple-choice over open-ended questions for nearly all our items, the survey was still long, with 45 questions and 135 items. Though there are few studies that demonstrate an 'ideal' number of items for a survey, the longer a survey takes to complete, the more likely individuals are to "drop out" of the survey (Dillman et al., 2014, p. ; Moss, 1981). The

Table 10 Effect of Factors on Percentage of Critical Questions Completed

\begin{tabular}{|c|c|c|c|c|c|c|c|c|}
\hline & \multicolumn{6}{|c|}{ Independent variables (Estimate, $P$ ) } & \multicolumn{2}{|c|}{ Model fit } \\
\hline & \multicolumn{2}{|c|}{ Incentive Timing } & \multirow{2}{*}{\multicolumn{2}{|c|}{$\begin{array}{c}\text { Mode Choice } \\
-\end{array}$}} & \multirow{2}{*}{\multicolumn{2}{|c|}{$\frac{\text { Urbanicity }}{-}$}} & F-Statistic & R2 \\
\hline Model 1 & $-1.6 \%$ & 0.344 & & & & & 0.90 & 0.00 \\
\hline Model 2 & \multicolumn{2}{|c|}{-} & $0.5 \%$ & 0.799 & \multicolumn{2}{|c|}{-} & 0.07 & 0.01 \\
\hline Model 3 & \multicolumn{2}{|c|}{-} & \multicolumn{2}{|c|}{-} & $-4.7 \%$ & 0.005 & 8.37 & 0.06 \\
\hline Model 4 & $-1.6 \%$ & 0.337 & $0.7 \%$ & 0.753 & \multicolumn{2}{|c|}{ - } & 0.50 & 0.01 \\
\hline Model 5 & $-1.4 \%$ & 0.397 & \multicolumn{2}{|c|}{ - } & $-4.7 \%$ & 0.005 & 4.54 & 0.05 \\
\hline Model 6 & \multicolumn{2}{|c|}{-} & $0.7 \%$ & 0.713 & $-4.7 \%$ & 0.005 & 4.22 & 0.05 \\
\hline Model 7 & $-1.4 \%$ & 0.386 & $0.8 \%$ & 0.675 & $-4.6 \%$ & 0.005 & 3.06 & 0.05 \\
\hline
\end{tabular}


low response rate, and therefore the small sample size, do limit our ability to generalise the results. A survey with a larger sample size may be able to uncover more results of statistical significance than those presented in this study.

Lastly, financial and logistic constraints prevented a more expansive research design, such as including additional approaches to examine the interaction of response mode choice and incentive timing or that varied the contact letter as mentioned in the Methods section of this paper. An additional omission to our study design was a pure "control" group that received no incentive or option in how to respond. Past research suggests that this group would have the lowest response rate, as this approach would not reap the benefits suggested by past literature of supplying an incentive (Edwards et al., 2002) or choice of response mode (Millar and Dillman, 2011; Smyth et al., 2014), which, given resource constraints, was not an option we could willingly add. Therefore, this study only focused on the experimental factors that we could afford to control for and compare, though future research could incorporate these additional factors as well.

\section{Conclusions}

Our results showed that offering respondents a choice of two response modes (web response or mailed paper response) has no significant effect on response rate, response speed, or the number of questions completed in the survey compared to those who were only offered the option to respond on the web. We also found that the timing of a nonconditional incentive, that is, receiving a monetary incentive in the initial contact versus in the first follow-up, did not significantly affect response rate or the number of questions completed, but did result in a faster response time $(P<0.1)$. In instances where receiving a faster response is important, we recommend including an incentive in the first contact with potential participants.

In contrast to past research, we found that urban households were significantly more likely to respond, respond faster, and complete more of the survey than rural households. Though researchers may not always be able to dictate their target populations, particularly in project-based research where a project or projects often dictates the research context, they should be aware of the additional challenges inherent in surveying rural communities.

In our particular context, this may have to do with the subject matter of the survey and that, despite petroleum production being prominent in all four communities, rural and urban residents may have different relationships with the oil and gas industry and different views towards the sponsoring university. More research is needed to better understand why these differences between urban and rural communities exist - and, potentially, if they are growing - as the findings presented here largely contradict past survey literature. More research is also needed in regard to mode choice, as past literature has shown that when offered a choice of responding via the web versus mail, surveys with the choice of responding by mail have a statistically significantly higher response rate than surveys with only a web response option. Our study showed no significant difference between those with only a web response option and those with a choice between web and mail response, contradicting past literature.

There are currently few studies of survey methods in engineering and construction project and organisations research. As one of the first such studies, we aim to provide researchers with information regarding response rates and timing. We anticipate that more engineering and construction researchers will require participation and responses from the general public to inform policies; for instance, research on the impact of engineering projects on society, or public preference to address ageing infrastructure or strengthen infrastructure due to climate change. For this research, understanding survey response rate and mode are critical. Through this research, we contribute by providing information on our responses and how incentives and response mode choice affected these rates.

\section{References}

Ahn, S. and Lee, S. (2015), "Methodology for creating empirically supported Agent-Based simulation with survey data for studying group behavior of construc- 
tion workers", Journal of Construction Engineering and Management, Vol. 141 No. 1, p. 04014065. 10.1061/(ASCE)CO.1943-7862.0000918

Al Hurr, N. and Tashman, L. (2019), "Measuring the sustainability of transport system in Amman." International Conference on Transportation and Development 2019, American Society of Civil Engineers, Alexandria, Virginia, 171-183.

Al Qady, M. and Kandil, A. (2013), "Document management in construction: practices and opinions", Journal of Construction Engineering and Management, Vol. 139 No. 10, p. 06013002. 10.1061/ (ASCE)CO.1943-7862.0000741

Amato, P.R. (1993), "Urban-Rural differences in helping friends and family members", Social Psychology Quarterly, Vol. 56 No. 4, 249. 10.2307/2786662

Asch, D.A., Jedrziewski, M.K. and Christakis, N.A. (1997), "Response rates to mail surveys published in medical journals", Journal of Clinical Epidemiology, Vol. 50 No. 10, pp. 1129-1136. 10.1016/S08954356(97)00126-1

Berry, S.H. and Kanouse, D.E. (1987), "Physician response to a Mailed survey an experiment in timing of payment", Public Opinion Quarterly, Vol. 51 No. 1, pp. 102-114. 10.1086/269018

Biswas, S., Hashemian, L. and Bayat, A. (2018), "Investigation of Pothole severity and maintenance methods in Canada through questionnaire survey", Journal of Cold Regions Engineering, Vol. 32 No. 2, p. 04018002. 10.1061/(ASCE)CR.19435495.0000161

Delnevo, C.D., Abatemarco, D.J. and Steinberg, M.B. (2004), "Physician response rates to a mail survey by specialty and timing of incentive", American Journal of Preventive Medicine, Vol. 26 No. 3, pp. 234-236. 10.1016/j.amepre.2003.12.013

Dillman, D.A., Smyth, J.D. and Christian, L.M. (2014), Internet, Phone, Mail and Mixed-Mode Surveys: The Tailored Design Method, Hoboken, NJ, John Wiley.

Edwards, P., Roberts, I., Clarke, M., DiGuiseppi, C., Pratap, S., Wentz, R. and Kwan, I. (2002), "Increasing response rates to postal questionnaires: systematic review", BMJ, Vol. 324 No. 7347, 1183. 10.1136/bmj.324.7347.1183

Emerson, R.M. (1976), "Social exchange theory", Annual Review of Sociology, Vol. 2 No. 1, pp. 335-362. 10.1146/annurev.so.02.080176.002003

Farnsworth, C.B., Warr, R.O., Weidman, J.E. and Mark Hutchings, D. (2016), "Effects of CM/GC project delivery on managing process risk in transportation construction", Journal of Construction Engineering and Management, Vol. 142 No. 3, p. 04015091. 10.1061/(ASCE)CO.1943-7862.0001091

Garcia-Cuerva, L., Schmidt, M., Berglund, E.Z. and Binder, A.R. (2015), "Results of a National Survey about the Public Acceptability of Reclaimed Water", World Environmental and Water Resources Congress 2015. Austin, TX, American Society of Civil Engineers. pp. 1231-1237.

Gendall, P. (2005), "The effect of covering letter Personalisation in mail surveys", International Journal of Market Research, Vol. 47 No. 4, pp. 365-380. 10.1177/147078530504700404

Groves, R.M., Cialdini, R.B. and Couper, M.P. (1992), "Understanding the decision to participate in a survey", Public Opinion Quarterly, Vol. 56 No. 4, 475. 10.1086/269338

Groves, R.M. and Peytcheva, E. (2008), “The impact of nonresponse rates on nonresponse bias: a metaanalysis", Public Opinion Quarterly, Vol. 72 No. 2, pp. 167-189. 10.1093/poq/nfn011

Grubert, E. (2018), "The Eagle Ford and Bakken shale regions of the United States: a comparative case study", The Extractive Industries and Society, Vol. 5 No. 4, pp. 570-580. 10.1016/j.exis.2018.09.011

Hacker, M.E., Kaminsky, J. and Faust, K.M. (2019), "Legitimizing involvement in emergency Accommodations: water and wastewater utility perspectives", Journal of Construction Engineering and Management, Vol. 145 No. 4, p. 04019013. 10.1061/ (ASCE)CO.1943-7862.0001622

Hanna, A.S., Thomas, G. and Swanson, J.R. (2013), "Construction risk identification and allocation: cooperative approach", Journal of Construction Engineering and Management, Vol. 139 No. 9, pp. 10981107. 10.1061/(ASCE)CO.1943-7862.0000703

Hawes, J.M., Crittenden, V.L. and Crittenden, W.F. (1987), "Effects of Personalization, source, and offer on mail survey response rate and speed", Akron business and economic review, Vol. 18 No. 2, pp. No. 54-63.

House, J.S. and Wolf, S. (1978), "Effects of urban residence on interpersonal trust and helping behavior", Journal of Personality and Social Psychology, Vol. 36 No. 9, 1029-1043. 10.1037/0022-3514.36.9.1029

Houston, M.J. and Jefferson, R.W. (1975), "The negative effects of Personalization on response patterns in mail surveys", Journal of Marketing Research, Vol. 12 No. 1, 114-117. 10.1177/002224377501200119

Judd, C.M., McClelland, G.H. and Ryan, C.S. (2017), Data Analysis: A Model Comparison Approach to Regression, ANOVA, and Beyond, New York, Routledge.

Engineering Project Organization Journal

(C) 2020 Engineering Project Organization Society www.epossociety.org 
Kaminsky, J.A. and Faust, K.M. (2017), “Transitioning from a human right to an infrastructure service: water, wastewater, and displaced persons in Germany", Environmental Science \& Technology, Vol. 51 No. 21, pp. 12081-12088. 10.1021/acs.est.7b03594

Kennedy, C., McGeeney, K. and Keeter, S. (2016), "The twilight of Landline interviewing: survey data quality tends to be at least as good when all interviewing is done with cellphones", Vol. 19.

Keranen, K.M., Weingarten, M., Abers, G.A., Bekins, B.A. and Ge, S. (2014), "Sharp increase in central Oklahoma seismicity since 2008 induced by massive wastewater injection", Science, Vol. 345 No. 6195, pp. 448-451. 10.1126/science. 1255802

Lee, J. (2016), “Impact of neighborhood Walkability on trip generation and trip Chaining: case of Los Angeles", Journal of Urban Planning and Development, Vol. 142 No. 3, p. 05015013. 10.1061/(ASCE) UP.1943-5444.0000312

McKenzie-McHarg, K., Tully, L., Gates, S., Ayers, S. and Brocklehurst, P. (2005), "Effect on survey response rate of hand written versus printed signature on a covering letter: randomised controlled trial [ISRCTN67566265", BMC Health Services Research, Vol. 5 No. 1, 52. 10.1186/1472-6963-5-52

Medway, R.L. and Fulton, J. (2012), "When more gets you less: a meta-analysis of the effect of concurrent web options on mail survey response rates", Public Opinion Quarterly, Vol. 76 No. 4, pp. 733-746. 10.1093/poq/nfs047

Millar, M.M. and Dillman, D.A. (2011), "Improving response to web and Mixed-Mode surveys", Public Opinion Quarterly, Vol. 75 No. 2, pp. 249-269. 10.1093/poq/nfr003

Moss, G.M. (1981), "Factors affecting response rate and response speed in a mail survey of part-time university students", Canadian Journal of Higher Education, Vol. 11 No. 2, pp. No. 79-89.

Olivieri, H., Seppänen, O., Alves, TdaC.L., Scala, N.M., Schiavone, V., Liu, M. and Granja, A.D. (2019), "Survey comparing critical path method, last Planner system, and Location-Based techniques", Journal of Construction Engineering and Management, Vol. 145 No. 12, p. 04019077. 10.1061/ (ASCE)CO.1943-7862.0001644

Osman, K.K., Claveria, J.B., Faust, K.M. and Hernandez, S. (2019), “Temporal dynamics of willingness to pay for alternatives that increase the reliability of water and wastewater service", Journal of Construction Engineering and Management, Vol. 145 No. 7, p. 04019041. 10.1061/(ASCE)CO.19437862.0001668
Pew Research Center (2018), "Internet/Broadband fact sheet".

Poleacovschi, C., Javernick-Will, A. and Tong, T. (2017), "The link between knowledge sharing connections and employee time savings: a social network analysis", Construction Management and Economics, Vol. 35 No. 8-9, pp. 455-467. $10.1080 / 01446193.2017 .1287414$

Rubinstein, J.L. and Mahani, A.B. (2015), "Myths and facts on wastewater injection, hydraulic fracturing, enhanced oil recovery, and induced Seismicity", Seismological Research Letters, Vol. 86 No. 4, pp. 1060-1067. 10.1785/0220150067

Sauermann, H. and Roach, M. (2013), "Increasing web survey response rates in innovation research: an experimental study of static and dynamic contact design features", Research Policy, Vol. 42 No. 1, pp. 273-286. 10.1016/j.respol.2012.05.003

Skipper, C.O. and Brandenburg, S. (2013), "Emotional intelligence and academic performance of engineering students", Engineering Project Organization Journal, Vol. 3 No. 1, pp. 13-21. 10.1080/21573727.2012.738669

Smyth, J.D., Dillman, D.A., Christian, L.M. and O'Neill, A.C. (2010), "Using the Internet to survey small towns and communities: limitations and possibilities in the early 21 st century", American Behavioral Scientist, Vol. 53 No. 9, pp. 1423-1448.

Smyth, J.D., Olson, K. and Millar, M.M. (2014), "Identifying predictors of survey mode preference", Social Science Research, Vol. 48, pp. 135-144. 10.1016/j.ssresearch.2014.06.002

Stafford, L. (2008), "Social Exchange Theories: Calculating the Rewards and Costs of Personal Relationships", Engaging Theories in Interpersonal Communication: Multiple Perspectives, Thousand Oaks, California, SAGE Publications Inc.

Steblay, N.M. (1987), "Helping behavior in rural and urban environments: a meta-analysis", $P s y$ chological Bulletin, Vol. 102 No. 3, pp. 346-356. 10.1037/0033-2909.102.3.346

Steeh, C.G. (1981), "Trends in nonresponse rates, 1952-1979", Public Opinion Quarterly, Vol. 45 No. 1, pp. 40-57. 10.1086/268633

Taylor, J.E. and Jaselskis, E.J. (2010), "Introduction to the special issue on research methodologies in construction engineering and management", Journal of Construction Engineering and Management, Vol. 136 No. 1, pp. 1-2. 10.1061/(ASCE)CO.19437862.0000141

The American Association for Public Opinion Research (2016), "Standard Definitions: Final Dispositions

Engineering Project Organization Journal

(C) 2020 Engineering Project Organization Society www.epossociety.org 
of Case Codes and Outcome Rates for Surveys.", AAPOR.

Toole, T.M., Hallowell, M. and Chinowsky, P. (2013), "A tool for enhancing innovation in construction organizations", Engineering Project Organization Journal, Vol. 3 No. 1, pp. 32-50. 10.1080/21573727.2012.717531

Tversky, A. and Shafir, E. (1992), “Choice under conflict: the dynamics of deferred decision", Psychological Science, Vol. 3 No. 6, pp. 358-361. 10.1111/j.1467-9280.1992.tb00047.x

US Census Bureau (2019), "United States Census Bureau Quick Facts", available at: https://www.census. gov/quickfacts/fact/table/edmondcityoklahoma/ PST045216.

USGS (2020), “USGS Earthquakes Hazard Program”, Latest Earthquakes, Database, available at: https:// earthquake.usgs.gov/earthquakes/.
Yeck, W.L., Sheehan, A.F., Benz, H.M., Weingarten, M. and Nakai, J. (2016), "Rapid response, monitoring, and mitigation of induced Seismicity near Greeley, Colorado", Seismological Research Letters, Vol. 87 No. 4, pp. 837-847. $10.1785 / 0220150275$

Zeglovits, E. and Schwarzer, S. (2016), "Presentation matters: how mode effects in item nonresponse depend on the presentation of response options", International Journal of Social Research Methodology, Vol. 19 No. 2, pp. 191-203. 10.1080/13645579.2014.978560

Zerio, A., Opdyke, A. and Javernick-Will, A. (2016), "Characterizing post-disaster reconstruction training methods and learning styles", Engineering Project Organization Journal, Vol. 6 No. 2-4, pp. 142-154. $10.1080 / 21573727.2016 .1257484$ 